\title{
Differences in perceived fairness and health outcomes in two injury compensation systems: a comparative study
}

Nieke A. Elbers ${ }^{1 *}$, Alex Collie², Sheilah Hogg-Johnson ${ }^{3}$, Katherine Lippel ${ }^{4}$, Keri Lockwood ${ }^{1}$ and lan D. Cameron ${ }^{1}$

\begin{abstract}
Background: Involvement in a compensation process following a motor vehicle collision is consistently associated with worse health status but the reasons underlying this are unclear. Some compensation systems are hypothesised to be more stressful than others. In particular, fault-based compensation systems are considered to be more adversarial than no-fault systems and associated with poorer recovery. This study compares the perceived fairness and recovery of claimants in the fault-based compensation system in New South Wales (NSW) to the no-fault system in Victoria, Australia.
\end{abstract}

Methods: One hundred eighty two participants were recruited via claims databases of the compensation system regulators in Victoria and NSW. Participants were $>18$ years old and involved in a transport injury compensation process. The crash occurred 12 months $(n=95)$ or 24 months ago $(n=87)$. Perceived fairness about the compensation process was measured by items derived from a validated organisational justice questionnaire. Health outcome was measured by the initial question of the Short Form Health Survey.

Results: In Victoria, $84 \%$ of the participants considered the claims process fair, compared to $46 \%$ of NSW participants $\left(x^{2}=28.54 ; p<.001\right)$. Lawyer involvement and medical assessments were significantly associated with poorer perceived fairness. Overall perceived fairness was positively associated with health outcome after adjusting for demographic and injury variables (Adjusted Odds Ratio $=2.8,95 \% \mathrm{Cl}=1.4-5.7, p=.004$ ).

Conclusion: The study shows large differences in perceived fairness between two different compensation systems and an association between fairness and health. These findings are politically important because compensation processes are designed to improve recovery. Lower perceived fairness in NSW may have been caused by potential adversarial aspects of the scheme, such as liability assessment, medical assessments, dealing with a third party for-profit insurance agency, or financial insecurity due to lump sum payments at settlement. This study should encourage an evidence informed discussion about how to reduce anti-therapeutic aspects in the compensation process in order to improve the injured person's health.

Keywords: Motor vehicle crash, Injury, Claimants, Procedural justice, Compensation systems

\footnotetext{
*Correspondence: nieke.elbers@sydney.edu.au

'John Walsh Centre for Rehabilitation Research, Sydney Medical School

Northern, University of Sydney, Sydney, Australia

Full list of author information is available at the end of the article
} 


\section{Background}

Each year, in Australia, about 100,000 people acquire an injury after a motor vehicle crash [1]. An estimated $50 \%$ of those lodge a compensation claim [2, 3]. They seek reimbursement for their damages, such as medical costs, loss of wages, and pain and suffering. Although the compensation process is supposed to improve recovery following injury, empirical literature indicates the contrary. People who lodge a compensation claim tend to show poorer recovery than those with similar injuries who do not claim [4-6]. The literature mainly distinguishes two explanations. The first is that injured claimants might not recover because there is a financial incentive not to get better as long as the claim process lasts (secondary gain) [7]. The second is that claimants have poorer recovery because of stress related to the compensation process. This is called secondary victimisation: first, people become a victim of the accident, then of the compensation system [8,9].

The support for the latter theory comes from both quantitative and qualitative studies. According to these studies, compensation stress is caused by stressful interactions with insurers, many medico-legal assessments, limited and impersonal communication, lack of information, delayed reimbursement of medical costs and loss of income, being confronted with significant paperwork, and feelings of stigmatization and power imbalance between claimants and the other actors in the system [10-15]. Quantitative studies have not measured the claimant's experiences of all these elements in one study, holistically. Furthermore, no study has been published yet comparing the experiences in different compensation systems. Measuring experiences of different claim aspects and comparing the experiences between jurisdictions is important, because it can give guidance about how to improve the compensation system.

The current study investigated the injured persons' perceived fairness regarding all the claim elements in the compensation system together. The perceived fairness was compared in two systems, the scheme in New South Wales (NSW) and the scheme in Victoria, two neighbouring states in Australia. The main differences are: (i) The scheme in NSW is mainly fault-based which means that claimants have to prove that the other person was at-fault (the insurance company will perform a liability assessment to determine whether the other person was at-fault), whereas the scheme in Victoria is mainly nofault, which means that claimants are compensated regardless of whether they or others were at-fault or not; (ii) In NSW medical assessments are relatively common and are conducted by a medical practitioner assigned by the insurance company, whereas in Victoria independent medical assessments are uncommon during the first 18 months of a claim; (iii) In NSW people receive a lump sum at settlement, including loss of income up to $100 \%$ of previous earnings, whereas Victoria has intermittent payments every two weeks, including loss of income payments for those working at the time of injury, which generally replace $80 \%$ of pre-accident earnings; (iv) In NSW, insurance is provided by seven private sector third-party insurers. Third-party insurance means that claimants deal with the insurance company of the person that caused the accident. The insurer in Victoria is the state government compensation authority, which is also the compensation system regulator and which recovers insurance premiums from all motor vehicles registered in the state, a sort of 'first-party insurance'. More detailed information about both systems is provided in Table 1.

The aim of the study was to compare the perceived fairness and health status of injured people claiming benefits through the compensation systems in NSW and Victoria. The no-fault compensation system in Victoria is hypothesised to be perceived as fairer and less stressful than in NSW, because the NSW system includes more adversarial components, such as the assessment of liability, medical assessments, lump sum payments and third-party insurance. It is also hypothesised that claimants in NSW would report poorer health outcomes than in Victoria due to these more adversarial components. To minimise potential cofounding, we adjusted for demographic characteristics, such as age, gender, socioeconomic status and marital status.

\section{Method \\ Participants}

Participants were recruited via two large databases that hold personal injury claims information after a motor vehicle collision in Victoria and NSW. Using the rule of thumb to have 10-15 participants per predictor [16], we sought to recruit about 200 participants to allow for 15 independent variables in a regression model. Since we included two states, we aimed to recruit 100 participants per state.

In NSW, participants were selected from the claim database held by the Motor Accidents Authority (MAA). The MAA is the state government regulator of the seven third-party insurance companies dealing with personal injury compensation claims in NSW. Recruitment letters were sent to those who were over 18 years old, whose crash occurred 12 or 24 months ago, and whose claim was accepted. Only accepted claims were included because people whose claims are denied have only limited exposure to the compensation scheme. Equal numbers of people 12 and 24 months after injury were approached. Twelve and 24 months are common time points in compensation and health research [13, 17]. Each compensation system and each claim has different 
Table 1 Comparison of the Victorian and NSW compensation scheme design

\begin{tabular}{|c|c|c|}
\hline & NSW motor accidents scheme & Victoria transport accident scheme \\
\hline \multicolumn{3}{|l|}{ Scheme structure and administration } \\
\hline 1. Legislation & Motor Accidents Compensation Act & Transport Accident Act \\
\hline $\begin{array}{l}\text { 2. What type of law governs the scheme: } \\
\text { no-fault, hybrid, common law? }\end{array}$ & $\begin{array}{l}\text { Hybrid. Mainly fault. Injured people have to } \\
\text { prove that somebody else was at-fault. } \\
\text { People can lodge a no-fault claim regardless } \\
\text { of fault up to } \$ 5000 \text {. } \\
\text { No-fault claims were excluded in this study. }\end{array}$ & $\begin{array}{l}\text { Hybrid. Mainly no-fault. Injured people } \\
\text { can claim regardless of fault. People with } \\
\text { serious injury have access to common law, } \\
\text { which is fault-based. } \\
\text { Common law claims were excluded in } \\
\text { this study. }\end{array}$ \\
\hline
\end{tabular}

3. Is the compensation scheme mechanism-based or disability-based?

4. How does the compensation system interact with other societal structures?

5. Is the insurance compulsory? How is the scheme funded?

6. Does the jurisdiction insure through private carriers or a state insurance fund?

Scheme eligibility

7. Is liability assessment a feature of the scheme?

8. What proportion of the total transport injury population is covered by the scheme? How is the total transport injury population defined?

9. Which injuries and afflictions are covered and which are not? Are mental health claims covered?

10. What is the time frame to lodge a claim?

Medical assessments

11. Who conducts the medical assessments? What is the role of the physician in injury certification and fitness for work?

Scheme benefits and entitlements

12. What benefits are paid for?

13. What is the level of income benefits/loss of wages? Are there caps on the wages earned?

Mechanism-based (injury resulting from motor vehicle/land-based transport accident)

Both systems purchase healthcare from national publicly funded and private healthcare systems. Both have involvement with legal systems for dispute resolution.

Compulsory insurance. Funded by annual insurance premiums paid by motor vehicle owners as part of registration.

7 Third party private insurance companies (profit)

1 First party state government compensation agency (non-profit)

Yes. Liability is assessed within 3 months after claim lodgement

No. Coverage is accepted for all transport accident related injuries.

The transport injury population are those who are injured in a transport accident that occurred in the state under investigation (respectively Victoria or NSW) AND anyone traveling in a vehicle registered by that particular state (respectively Victoria or NSW) in any part of Australia

All injuries arising from the transport accident are covered including mental injury.

The fault-based claim has to be lodged within 6 months post-injury

Medical assessments are conducted by doctors assigned by the insurance company or assigned by the injured person's lawyer. For disputed medical assessments there is an independent medical assessment service

Compensation can be paid for medical and rehabilitation services, past (i.e. between injury and claim settlement) and future (i.e. after claim settlement) income replacement, travel, and household support, legal services, and pain and suffering

Loss of wages involves $100 \%$ of previous/future salary. Capped at $\$ 4,412$ net weekly earning (2014). Payments are tax-free, provided certain conditions are met.
The no-fault claim has to be lodged within 12 months post-injury

$<18$ months: assessments are conducted by injured person's general practitioner. $>18$ months: there is a change in income replacement benefits so people still on benefits at this time commonly undergo a medical assessment by an assessor nominated by the TAC to determine work capacity

No-fault benefits include medical and rehabilitation services, income replacement, travel, and household support. Legal costs related to disputes (protocol disputes and Victorian Civil Appeals Tribunal) are reimbursed.

The claimant has to cover the first 5 working days before compensation of loss of earnings commences.

$<18$ months: Income benefits will generally be $80 \%$ of pre-accident weekly earnings, capped to a maximum of $\$ 1,250$ per week $(2014 / 15)$. Clients who were earning less than $\$ 612$ will get $100 \%$ of the pre-accident earnings. These payments are taxed.

$>18$ months: Based on work capacity assessment. Payments are capped at $\$ 1,060$ per week and they are not taxed.

$>36$ months: Continuing benefits only with an impairment of at least $50 \%$ 
Table 1 Comparison of the Victorian and NSW compensation scheme design (Continued)

14. What is the duration and frequency of payments?

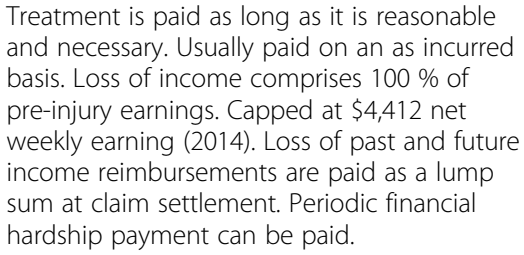

Treatment is paid as long as it is reasonable and necessary. Usually paid on an as incurred basis. Loss of income comprises $100 \%$ of pre-injury earnings. Capped at $\$ 4,412$ net weekly earning (2014). Loss of past and future income reimbursements are paid as a lump sum at claim settlement. Periodic financial hardship payment can be paid.

Treatment is paid as long as it is reasonable and necessary. Usually paid on an as incurred basis. Income benefits for no-fault claims are limited to 3 years from the accident unless they have a permanent impairment level of at least $50 \%$. Income benefits are paid fortnightly. Claims do not formally close.

Scheme Changes

15. Has the compensation scheme undergone any significant changes

No changes during the study period.

The claims process changed in October 2013. The main changes with respect to perceived fairness were an easier claims form and faster approval of services. Also a joint medical examination process was introduced reducing the number of medical assessments.

Table is based on information derived from the Transport Accident Act [33] and Motor Accidents Compensation Act [34] and checked by policy makers of both schemes. We used the format developed by Clay et al. [35] adapted for motor vehicle injury insurance schemes

times at which things happen, so for the purpose of measuring the impact of the compensation system as a whole, general timeframes are chosen. Participants could opt-in by contacting the primary investigator [NE]. Those who had not replied were reminded at random, which continued until the required number of 100 participants was met. An experienced research nurse [KLo] conducted the interview by telephone. Verbal informed consent was obtained.

In Victoria, participants were selected from the claims database held by the Transport Accident Commission (TAC). The TAC is the state government-run first-party compensation agency dealing with compensation claims in Victoria. Recruitment letters were sent to people who were already enrolled in an on-going survey run by the TAC. The sample from the on-going TAC survey was considered representative for the Victorian claimant population. We sent letters to those who were over 18 years old, whose crash occurred 12 and 24 months ago, and whose claim was accepted. Equal numbers of people (12 and 24 months after injury) were approached. People could opt-out of the current study by contacting the Social Research Centre, which is an independent research organization that conducted the research on the TAC's behalf. The Social Research Centre conducted the telephone interview. The research ethics committee of The University of Sydney approved the study.

\section{Questionnaire}

The telephone interview involved a structured questionnaire consisting of seven categories: demographic variables, claim process, lawyer involvement, medical assessments, dispute resolution, health status, and work status.

\section{Demographic and injury factors}

Demographic variables included age at time of the interview, gender, country of birth, postcode, highest education, and marital status. Socio-economic status (SES) was obtained by matching participants' postcodes to a Census Collection District [18] (scale from 1 to 10; 1 = lowest SES, $10=$ highest SES). Injury data was derived from the claims databases: (1) the type of injury, which is determined by trained insurance company personnel at the initial interview with the claimant, (2) number of days in the hospital. Time since the accident was either 12 or 24 months.

\section{Claim factors}

Claim factors were lawyer involvement (yes/no), medical assessments assigned by the insurance/compensation agency (yes/no), and if yes, the number of assessments, dispute process (yes/no), claim status (NSW: yes/no, Victoria: claims do not close, so a proxy was used whether the claim was inactive for more than 6 months yes/no, which was derived from the claims database. Six months of inactivity is a timeframe used by the TAC, which is based on years of experience. A claim is considered inactive if there has not been any payment or correspondence between the $\mathrm{TAC}$ and the claimant for 6 months since the last payment/correspondence), previous claim (NSW: yes/no, Victoria: derived from the claims database), and whether the injured person was at fault or not (NSW: since they all have an accepted faultbased claim they have successfully proven that somebody else was at fault, so the NSW participants were indicated as being not-at-fault. It should be noted that claimants could have contributed to the harm they suffered through their own negligence, but they were still classified not-at-fault; Victoria: totally at fault, partially at fault, not at all at fault. We did not gather information as to whether someone else was at fault).

\section{Health and work status}

Participants were asked to rate their general health preinjury and their general health at the moment of the 
interview. Both were based on the first question of the SF12 [19], using a 5 point Likert scale: excellent to poor. Work status was determined by the question whether the participant was currently working part time or full time (yes/no). If not, they were asked whether they were unable to work permanently or temporarily or not working for some other health reason.

\section{Fairness perceptions}

The fairness perceptions were clustered into 5 themes: claims process, claims management, medical assessments, lawyer involvement, and dispute resolution processes. Questions were mainly based on items of a validated organisational justice questionnaire [20], which has been applied to the compensation process in previous studies $[17,21]$. Several questions were added through discussion with the TAC and MAA and based on the literature. Fairness questions were followed by a 5 point Likert answer scale (strongly disagree - strongly agree).

\section{Claims process}

To assess the general aspects of the claims process, participants were asked whether the amount of reimbursement they received so far was fair and acceptable (distributive justice). In addition, six self-developed questions were added to address other claim issues, such as whether it was difficult to fill in the forms, and whether the duration of the claim (so far) was acceptable.

\section{Claims management}

Participants were asked about the interaction with the claims manager: e.g. 'the claims manager has taken into account my views and feelings during the claims management process' (procedural justice), 'the claims manager has provided me with the information I needed' (informational justice), and 'the claims manager treated me politely' (interpersonal justice). Three questions were added about the approval of treatment requests and the promptness of approval of other services.

\section{Lawyer involvement}

In those cases in which the participants involved a lawyer, they were asked why a lawyer was needed (openended question), followed by three questions about the information provided by the lawyer (informational justice) and two questions about whether they received polite and respectful treatment (interpersonal justice). A final question concerned a self-developed item asking whether the lawyer made the claims process easier.

\section{Medical assessments}

If participants had attended an examination requested by the insurer/TAC, they were asked whether the number of medical assessments was acceptable. In addition, we asked whether the medical assessor had provided them with the information they needed, whether they carefully explained what was going to happen during the examination and whether the medical assessor examined them in an unbiased and objective way (informational justice). In addition, two questions addressed whether the medical assessor treated them politely and respectfully (interpersonal justice).

\section{Dispute resolution}

Those who had indicated that they were involved in a formal dispute resolution process were asked whether the decision maker in the dispute process provided them with the information needed, whether the way the judgement was made was explained carefully, and whether the decision maker had communicated the judgement to the participant (informational justice) and whether they received polite and respectful treatment (interpersonal justice). Finally, it was asked whether the dispute process was stressful. All questions were followed by a 5 point Likert answer scale. Multi-item scales were asked in a random order in Victoria as consistent with the usual practice of the research centre.

\section{Statistical analyses}

In preparation of the analysis, several items were dichotomised: i.e. socio-economic status (low: $1-5$ versus high: 6-10), education (low-medium versus high - high is defined as undergraduate, bachelor and postgraduate), marital status (married/de facto versus single/divorced/ separated), type of injury (whiplash/soft tissue injury versus other), at-fault (totally versus not at all/partially), health (poor/fair versus good/very good/excellent) and all justice items (agree versus disagree/neutral). Type of injury was dichotomised into whiplash/soft tissue injury versus other type of injuries because whiplash is considered a problematic and very common injury in motor vehicle accident compensation systems [22].

Firstly, it was investigated whether participants in both samples had similar demographic characteristics. Secondly, we compared the fairness perceptions between NSW and Victoria. Pearson's chi-square (for categorical variables) and $\mathrm{t}$-tests (for continuous variables) were conducted. To check for selection bias, a non-response analysis was conducted comparing participants to those who received the recruitment letter but were not included. A NSW sub-sample analysis was conducted comparing whether the opt-in participants were different to those who were recruited through reminder phone calls.

Thirdly, it was investigated what factors are associated with the overall fairness perception. A multiple logistic regression analysis was conducted, with covariates added in two blocks, to model the probability that the process was considered fair (versus not fair/neutral). The first 
block included demographic and injury details; the second block added the claim factors. The claim factors were medical assessments, lawyer involvement, claim settlement, and previous claim. Dispute process (i.e. a formal internal appeal procedure, an external appeal procedure, or a civil trial in court) could not be included, because there were not enough participants involved in a dispute. 'At-fault' was not included because this variable only applies to the Victorian sample.

Finally, we explored whether the overall perceived fairness of the compensation process is associated with health status. Another multiple logistic regression analysis was conducted, with covariates added in two blocks, to model the probability of good or excellent health (versus fair or poor health). The first block explored the (unadjusted) association between the overall fairness perception and health. In the second block, demographic, injury variables, and health pre-injury are added.

IBM SPSS statistics software version 22 was used for all analyses.

\section{Results}

Participants

In NSW, 501 recruitment letters were sent out. In total, 25 participants opted in and 75 were included after a reminder phone call. After 100 participants were recruited, no further participants were sought. During the analysis, two participants were excluded because they were partners of injured people, they were not injured themselves, resulting in $98 \mathrm{NSW}$ participants. Responders in NSW were significantly older than the non-responders, $\mathrm{t}(499)=6.96$, $p<.001$, but gender and time since accident were similar $\left(\mathrm{X}^{2}=3.78, p=.052 ; \mathrm{X}^{2}=0.06, p=.805\right)$.

In Victoria, 149 participants were sent the information sheet, of which 103 participated. During the analysis, 19 were excluded because, after their data was linked with administrative data from the TAC, it was found that they had lodged a common law (i.e. fault-based) claim. Faultbased common law claims were excluded because the study design was to compare a fault-based system with a no-fault system. The fault-based common law claims in Victoria consist of a small category of severely injured people, experiencing a different system. This resulted in a total number of 84 Victorian participants. Nonresponse was somewhat higher in the $<25$ year old group than in the $>45$ year old group ( $42 \%$ versus $25 \%$; only summarised frequency data was available so no test could be performed), but for the variable 'time since injury' the non-response was similar: about $30 \%$ for both 12 months and 24 months after injury.

The total number of participants in NSW and Victoria was 182 . For 95 participants the injury occurred 12 months ago (NSW: 54; Victoria: 41), and 87 participants were included 24 months after injury (NSW: 44; Victoria: 43).
The interviews were conducted from April to July 2014. It took on average $15 \mathrm{~min}$ to complete one interview. The flow chart of participants is provided in Fig. 1.

\section{Sample characteristics}

The sample characteristics are displayed in Table 2.

\section{Demographic and injury variables}

The NSW participants were older, more likely to be female, more likely to suffer whiplash injury, and less likely to have been admitted to the hospital. Country of birth, marital status, education, socio-economic status, and time since injury were similar in both states.

\section{Claim factors}

Claimants in NSW were more likely to have a lawyer than those in Victoria (67\% versus $13 \%$ ). The percentage of participants that was medically assessed by an assessor assigned by the insurance company was higher in NSW than in Victoria (54 \% versus $10 \%$ ). For those who were assessed, the average number of assessments in NSW was similar to the average number in Victoria (two assessments on average). Three participants were involved in a dispute process: 2 in NSW and in 1 in VIC. In NSW, $26 \%$ of claims were settled compared to $45 \%$ inactive claims in Victoria. In NSW, $32 \%$ had lodged a previous claim, compared to $16 \%$ in Victoria. In NSW, all claimants were at least partially not-at-fault (they all had an accepted fault-based claim), whereas in Victoria $18 \%$ considered themselves completely at fault.

\section{Health and work}

Pre-injury health status was similar between states. Postinjury, the participants in NSW had poorer health outcomes in comparison to participants in Victoria. The number of people not working due to the injury was not significantly different between states (NSW: $12 \%$ vs Victoria: $18 \%$ ). A subgroup analysis of the NSW opt-in participants versus those who were recruited via reminder calls showed no differences in demographic, injury, claim, or health characteristics.

\section{Fairness perceptions}

The fairness statistics are provided in Table 3.

\section{Claims process}

In NSW, claimants consistently scored lower on all items of the claims process $(p<.001)$. The overall fairness of the compensation process involved the largest difference $\left(x^{2}=28.54\right)$, followed by the claim duration $\left(x^{2}=27.13\right)$. Participants in NSW were less likely to agree that it was easy to provide the information needed to support the claim $\left(x^{2}=23.00\right)$, or easy to fill in the forms $\left(x^{2}=17.75\right)$, and they were less likely to consider the compensation 


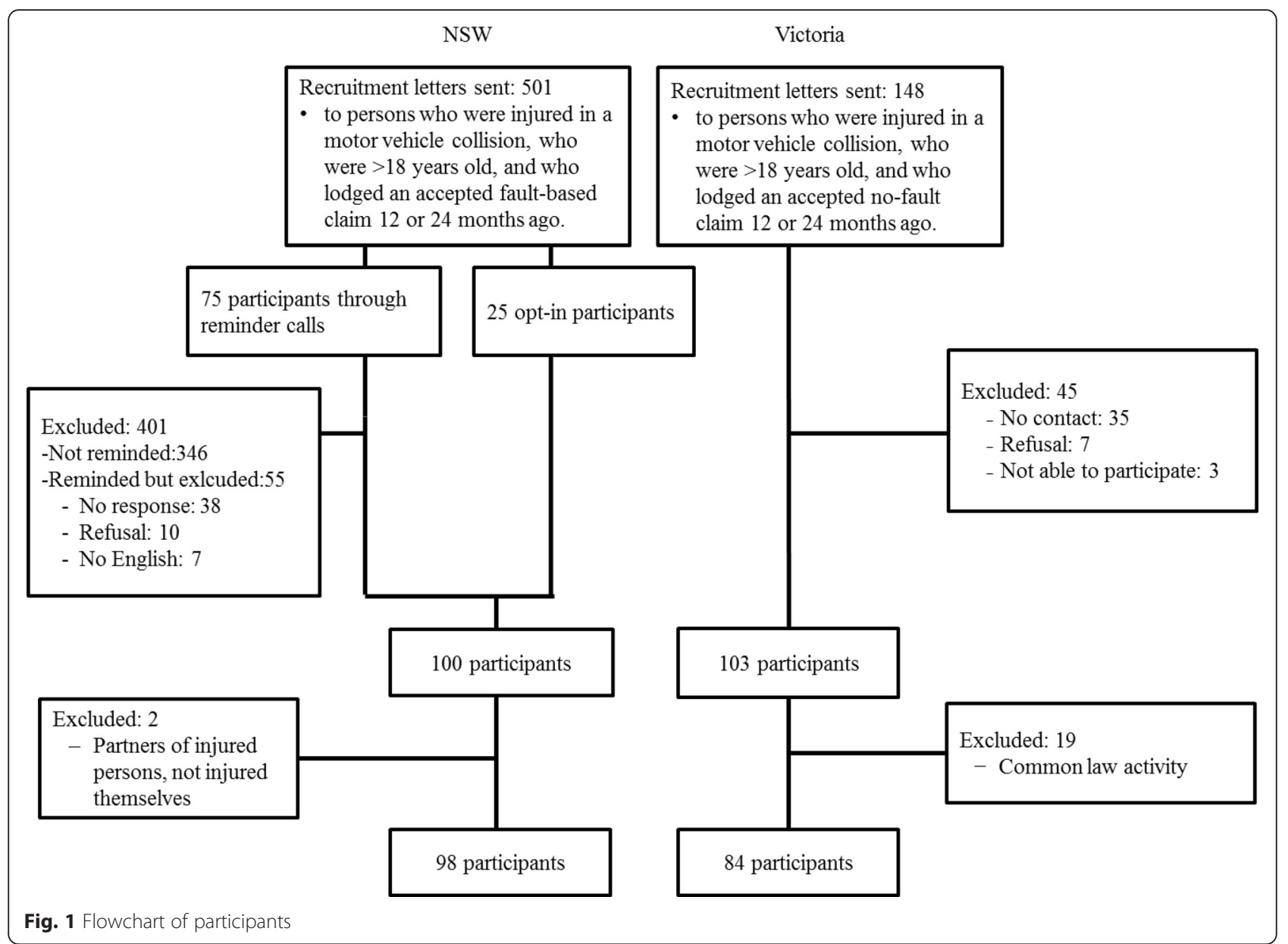

amount received so far to be fair compared to Victorians $\left(x^{2}=14.50\right)$. The percentage of participants who considered the different elements of the claims process to be fair ranged between 45 and $52 \%$ in NSW, compared to 74 and $85 \%$ in Victoria. The average fairness score of all claims process items was $3.06(\mathrm{SD}=0.81)$ in NSW and $3.81(\mathrm{SD}=0.90)$ in Victoria.

\section{Claims management}

NSW participants were more likely to report all actions of the claims manager to be less fair than participants in Victoria $(p<.001)$. The largest difference was reported on the item whether the claims manager managed the claim objectively $\left(X^{2}=50.29\right)$, followed by whether the claims manager used the correct information $\left(x^{2}=43.11\right)$, whether he/she explained what was going to happen $\left(x^{2}=\right.$ $38.15)$, and whether he/she provided the information that was needed $\left(x^{2}=30.56\right)$. Timely communication was also valued quite differently between the two states $\left(x^{2}=\right.$ 25.88). Whether the claims manager approved a treatment yielded a larger fairness gap between the two samples than whether the approval occurred promptly (resp. $\chi^{2}=28.84$ versus $\left.X^{2}=19.01\right)$. Whether the claims manager took the participant's views and feelings into account $\left(\chi^{2}=22.05\right)$, was polite $\left(\chi^{2}=19.90\right)$, and respectful $\left(\chi^{2}=19.58\right)$ resulted in a more modest difference. The percentage of participants perceiving the actions of the claims manager as fair ranged between 37 and $67 \%$ in NSW versus between 67 and $95 \%$ in Victoria. The average score for claims management by the insurance company in NSW was 3.19 $(\mathrm{SD}=0.90)$ and 3.94 ( $\mathrm{SD}=0.68)$ in Victoria. In both states, the lowest score was for the approval of other services to be prompt (services such as travel expenses, home or gardening services, medical investigations) and highest score was for politeness. A subgroup analysis of the NSW opt-in participants versus those who were recruited via reminder calls showed no differences in perceived fairness regarding the claims process or the claims manager.

\section{Medical assessments}

In both states, not many participants agreed they were given information by the medical assessor (NSW: $50 \%$, Victoria: $38 \%$ ), nor were they likely to agree that the medical assessors explained what was going to happen (52 \% in NSW; 63 \% in Victoria). The lowest scores were acquired on the item whether the medical assessor was 
Table 2 Sample characteristics, claim factors, health and work status

\begin{tabular}{|c|c|c|c|c|}
\hline \multirow[t]{2}{*}{ Demographic variables } & \multirow{2}{*}{$\begin{array}{l}\text { NSW }(n=98) \\
N(\%), M(S D)\end{array}$} & \multirow{2}{*}{$\begin{array}{l}\text { VIC }(n=84) \\
\text { N (\%), M (SD) }\end{array}$} & \multirow{2}{*}{$\begin{array}{l}x^{2} \text { or } t \\
\text { (df) }\end{array}$} & \multirow[t]{2}{*}{$p$} \\
\hline & & & & \\
\hline Age & $54.59(14.36)$ & $45.79(16.27)$ & $3.88(180)$ & $<.001$ \\
\hline Gender (male) & $52 / 98(53 \%)$ & $58 / 84(69 \%)$ & 4.84 & .028 \\
\hline Country of birth (Australia) & $67 / 98(68 \%)$ & $61 / 84(73 \%)$ & 0.39 & .531 \\
\hline Socio-economic status (high) & 46/98 (47 \%) & $51 / 84(61 \%)$ & 3.45 & .063 \\
\hline Education (high) & 25/98 (26 \%) & 26/83 (31\%) & 0.75 & .386 \\
\hline Marital status (married) & $54 / 98$ (55 \%) & 44/82 (54 \%) & 0.04 & .846 \\
\hline Injury (whiplash/soft tissue) & 39/98 (40 \%) & 15/84 (18 \%) & 10.43 & .001 \\
\hline Hospital (admitted) & 43/98 (48 \%) & $54 / 84(64 \%)$ & 7.57 & .006 \\
\hline Time since the accident (12 months) & $54 / 98(55 \%)$ & $41 / 84(49 \%)$ & 0.72 & .397 \\
\hline \multicolumn{5}{|l|}{ Claim factors } \\
\hline Lawyer & 66/98 (67 \%) & 11/84 (13\%) & 54.54 & $<.001$ \\
\hline Medically assessed & 53/98 (54 \%) & $8 / 83(10 \%)$ & 39.73 & $<.001$ \\
\hline Number of assessments & $1.66(1.02)$ & $2.29(1.38)$ & $-1.47(58)$ & .148 \\
\hline Dispute process & 2/98 (2 \%) & $1 / 84(1 \%)$ & - & - \\
\hline Claim status (settled/inactive) & 25/98 (26 \%) & 38/84 (45 \%) & 7.78 & .005 \\
\hline Previous claim & $31 / 98$ (32 \%) & 13/84 (16 \%) & 6.44 & .011 \\
\hline Fault (at-fault) & 0/98 (0 \%) & 14/79 (18 \%) & 18.86 & $<.001$ \\
\hline \multicolumn{5}{|l|}{ Health and work status } \\
\hline \multicolumn{5}{|l|}{ Health } \\
\hline Pre-injury (good-excellent) & 88/96 (92 \%) & 81/83 (98 \%) & 2.96 & .085 \\
\hline Post-injury (good-excellent) & 43/92 (47 \%) & $56 / 84(67 \%)$ & 7.09 & .008 \\
\hline Not working due to the accident ${ }^{a}$ & 12/98 (12\%) & 15/84 (18\%) & 1.13 & .288 \\
\hline
\end{tabular}

Notes. Socio-economic status (low $=1-5$ versus high $=6-10$ ), education (low-medium versus high; high is defined as undergraduate, bachelor and postgraduate), marital status (married/de facto versus single/divorced/separated), type of injury (whiplash/soft tissue injury versus other), at-fault (totally at fault versus not at all at fault/partially at fault), health (poor/fair versus good/very good/excellent)

at time of interview

unbiased (40\% versus $38 \%$ ). In both states, the majority perceived being treated politely (NSW: $67 \%$; Victoria: $75 \%$ ) and respectfully (NSW: $67 \%$; Victoria: $63 \%$ ). Agreement with the actions of the medical assessor ranged between 40 and $67 \%$ in NSW and 38 and $75 \%$ in Victoria. The average score given to the interaction with the medical assessor was $3.18(\mathrm{SD}=0.90)$ in NSW and $3.30(\mathrm{SD}=1.06)$ in Victoria. The number of medical assessments was considered to be acceptable by more respondents in Victoria than in NSW (88 versus $64 \%$ ).

\section{Lawyer involvement}

In both states, participants were very satisfied with the information (NSW: $86 \%$; Victoria : $80 \%$ ) and the explanations that the lawyer provided (NSW: $86 \%$; Victoria : $80 \%)$. The information was provided at the right time (NSW: $83 \%$; Victoria : $90 \%$ ). The lawyer was considered polite (NSW: $97 \%$; Victoria : $100 \%$ ) and respectful (NSW: $92 \%$; Victoria : $100 \%$ ). Agreement with the lawyers' behaviour ranged between $83 \%-97 \%$ in NSW compared to $80 \%-100 \%$ in Victoria. The average score given to the interaction with their lawyer was $4.02(\mathrm{SD}=$ $0.49)$ in NSW and $3.80(\mathrm{SD}=0.65)$ in Victoria. Participants indicated that the lawyer made the process easier (NSW: $85 \%$; Victoria: $73 \%$ ).

In both states, the main reason why participants involved a lawyer was because they believed they needed help/assistance/information in a process they were not familiar with and which they considered complicated (NSW: $36 / 66=55 \%$, Victoria: 5/11=45\%). Other reasons were that they were advised by others (NSW: $11 / 66=17 \%$, Victoria: $1 / 11=9 \%$ ), because they were not happy with a decision or outcome in the claims process (NSW: $7 / 66=11 \%$, Victoria: $2 / 11=18 \%$ ), or because the accident was not their fault/somebody else's fault and they wanted to be sure they were rightfully compensated (NSW: 7/66 $=11 \%$, Victoria: $2 / 11=18 \%)$.

\section{Dispute process}

Of the three participants who were involved in a dispute, the two participants in NSW were unhappy with the 
Table 3 Fairness perceptions about the claims process, claims management, medical assessments, lawyer involvement, and dispute process

\begin{tabular}{|c|c|c|c|c|}
\hline Claims process & NSW $^{a}$ & $\mathrm{VIC}^{\mathrm{a}}$ & $x^{2}$ & $P$ \\
\hline It is easy to fill out forms & 45/97 (46 \%) & $62 / 80(78 \%)$ & 17.75 & $<.001$ \\
\hline It is easy to support claim & 50/97 (52 \%) & 70/82 (85 \%) & 23.00 & $<.001$ \\
\hline Claim duration is acceptable & 44/96 (46 \%) & 70/84 (83 \%) & 27.13 & $<.001$ \\
\hline Compensation received so far is fair & 45/98 (46 \%) & 60/81 (74 \%) & 14.50 & $<.001$ \\
\hline Overall claim process is fair & 44/96 (46 \%) & 70/83 (84 \%) & 28.54 & $<.001$ \\
\hline \multicolumn{5}{|l|}{ Claims management } \\
\hline \multicolumn{5}{|l|}{ The claims manager... } \\
\hline takes views/feelings into account & 39/96 (39 \%) & $62 / 82(76 \%)$ & 22.05 & $<.001$ \\
\hline manages claim objectively & $41 / 96(42 \%)$ & 78/84 (93 \%) & 50.29 & $<.001$ \\
\hline uses correct information & 43/96 (45 \%) & 75/82 (92 \%) & 43.11 & $<.001$ \\
\hline provides information & 44/96 (46 \%) & 71/83 (86 \%) & 30.56 & $<.001$ \\
\hline explains procedure & 33/96 (34 \%) & $64 / 79(81 \%)$ & 38.15 & $<.001$ \\
\hline communicates timely & 39/95 (41 \%) & 66/84 (79 \%) & 25.88 & $<.001$ \\
\hline is polite & 66/96 (67 \%) & 78/82 (95 \%) & 19.90 & $<.001$ \\
\hline is respectful & 63/96 (64 \%) & 78/84 (93 \%) & 19.58 & $<.001$ \\
\hline approves treatment needed & $56 / 98(57 \%)$ & 76/82 (93 \%) & 28.84 & $<.001$ \\
\hline approves treatment promptly & $51 / 98$ (52 \%) & 68/82 (83 \%) & 19.01 & $<.001$ \\
\hline approves other services promptly & 37/98 (37 \%) & 49/73 (67\%) & 14.43 & $<.001$ \\
\hline
\end{tabular}

Medical assessments

The medical assessor...

provided information

explained procedure

examined unbiased

was polite

was respectful

Number of assessments was acceptable

Lawyer involvement

The lawyer..

provided information
explained procedure
communicated timely
was polite
was respectful

The lawyer made the process easier

Dispute process

Decision maker ..

$\begin{array}{lll}\text { provided information } & 0 / 2(0 \%) & 1 / 1(100 \%) \\ \text { explained procedure } & 0 / 2(0 \%) & 1 / 1(100 \%) \\ \text { communicated judgment } & 0 / 2(0 \%) & 1 / 1(100 \%) \\ \text { was polite } & 2 / 2(100 \%) & 1 / 1(100 \%) \\ \text { was respectful } & 2 / 2(100 \%) & 1 / 1(100 \%) \\ \text { Dispute process was stressful } & 2 / 2(100 \%) & 1 / 1(100 \%)\end{array}$

$\begin{array}{ll}26 / 52(50 \%) & 3 / 8(38 \%) \\ 27 / 52(52 \%) & 5 / 8(63 \%) \\ 21 / 52(40 \%) & 3 / 8(38 \%) \\ 35 / 52(67 \%) & 6 / 8(75 \%) \\ 35 / 52(67 \%) & 5 / 8(63 \%) \\ 34 / 53(64 \%) & 7 / 8(88 \%)\end{array}$

$57 / 66(86 \%)$

$8 / 10(80 \%)$

$8 / 10(80 \%)$

$8 / 10(90 \%)$

$11 / 11(100 \%)$

$11 / 11(100 \%)$

$8 / 11(73 \%)$

Notes. The answer scale to all justice questions was strongly agree, agree, neither agree nor disagree, disagree, strongly disagree, which was dichotomised into strongly disagree, disagree, neither agree nor disagree versus agree, strongly agree

${ }^{a}$ column displays the number of participants that strongly agreed/agreed with the statement divided by the total number of participants that answered the question

- = The number of participants is too small to conduct further analyses 
information, the explanations, and communication, whereas the one person from Victoria was satisfied. All three participants agreed that the decision maker was respectful and dignified, but they also all found the dispute process stressful.

Predictors of overall fairness of the compensation process The first model, in which only demographic and injury factors were included, showed that married participants were more likely to perceive the compensation process as fair than singles (Adjusted Odds Ratios $[\mathrm{AOR}]=2.11, p=.027)$. Furthermore, people with whiplash/soft tissue injuries were less likely to perceive the compensation process as fair than those with other types of injuries $(\mathrm{AOR}=0.43, p=.035)$. The second model, in which the claim factors were included, showed that being medically assessed (AOR = $0.31 ; p=.013)$ and having a lawyer involved $(\mathrm{AOR}=0.33$; $p=.016)$ were independently negatively associated with overall fairness of the compensation process. Marital status and injury type were no longer significant. There was no multicollinearity. The AOR's and p-values are shown in Table 4.

Table 4 Predictors overall fairness of the compensation process

\begin{tabular}{|c|c|c|c|c|c|c|c|c|}
\hline \multirow[t]{3}{*}{ Independent variables } & \multicolumn{8}{|c|}{ Overall fairness claims process } \\
\hline & \multicolumn{4}{|c|}{ Model 1} & \multicolumn{4}{|c|}{ Model 2} \\
\hline & $\mathrm{AOR}$ & $\mathrm{Cl}$ & & $p$ & $\mathrm{AOR}$ & $\mathrm{Cl}$ & & $p$ \\
\hline Age & 0.99 & 0.97, & 1.01 & .21 & 1.00 & 0.97 & 1.02 & .73 \\
\hline Gender & 0.75 & 0.38 & 1.48 & .41 & 0.79 & 0.37 & 1.68 & .54 \\
\hline Country of birth & 0.91 & 0.44 & 1.87 & .79 & 0.87 & 0.38 & 1.97 & .73 \\
\hline Socio-economic status & 1.84 & 0.95, & 3.56 & .07 & 1.38 & 0.65 & 2.94 & .41 \\
\hline Education & 0.58 & 0.28 & 1.21 & .15 & 0.46 & 0.20 & 1.06 & .07 \\
\hline Marital status & 2.11 & 1.09 & 4.06 & .03 & 1.69 & 0.81 & 3.55 & .16 \\
\hline Injury & 0.43 & 0.19 & 0.94 & .04 & 0.65 & 0.26 & 1.60 & .35 \\
\hline Hospital admission & 0.73 & 0.36 & 1.49 & .38 & 1.08 & 0.48 & 2.45 & .85 \\
\hline Time after injury & 1.04 & 0.54 & 1.99 & .91 & 1.08 & 0.48 & 2.44 & .86 \\
\hline Medical assessment & & & & & 0.31 & 0.12 & 0.78 & .01 \\
\hline Lawyer involvement & & & & & 0.33 & 0.13 & 0.81 & .02 \\
\hline Claim status & & & & & 1.71 & 0.68 & 4.32 & .26 \\
\hline Previous claim & & & & & 1.66 & 0.68 & 4.03 & .26 \\
\hline
\end{tabular}

Notes: Model 1 Nagelkerke $\mathrm{R}^{2}=.111$; Model 2 Nagelkerke $\mathrm{R}^{2}=.339$

Multiple logistic regression analysis, modelling the probability that the process was considered fair (versus not fair/neutral). The first model includes demographic and injury details. The second model adds the claim factors. 'At-fault' was not included because this variable only applies to the Victorian sample. There was no multicollinearity

Coding: Gender ( $0=$ Male; $1=$ Female); Country of birth $(0=$ Other; $1=$ Australia); Socio-economic status ( $0=$ Lower; $1=$ Higher); Education $(0=$ Low $/$ Medium; $1=$ High); Marital status ( $0=$ Single/Divorced; $1=$ Married); Injury ( $0=$ Other; $1=$ Whiplash $/$ soft tissue injury); Hospital admission $(0=\text { No; } 1=\text { Yes })_{;}$ Time after injury $(0=12$ months; $1=24$ months). Medical assessment $(0=\mathrm{No}$ $1=$ Yes); Lawyer involvement $(0=\mathrm{No} ; 1=$ Yes); Claim status $(0=$ Pending; $1=$ Settled); Previous claim $(0=\mathrm{No} ; 1=$ Yes); Overall fairness claims process $(0=$ not fair $/$ neutral, $1=$ fair $)$. Reference category $=0$

\section{Predictors of health post-injury}

The first model, which investigated the unadjusted association, showed a significant positive interaction between overall fairness perception of the compensation process and health post-injury ( $\mathrm{OR}=2.78, p=.002)$. The second model, which adjusted for demographic and injury characteristics, showed that the association between fairness and health was of the same magnitude after adjustment ( $\mathrm{AOR}=2.83, p=.004)$. Additionally, health pre-injury was associated with health post-injury (AOR $=6.15, p=.039$ ). There was no multicollinearity. The AOR's and $p$-values are shown in Table 5.

\section{Discussion}

The study investigated whether there were differences in perceived fairness between two injury compensation schemes of different design. The findings reported here suggest the answer to this question is yes. Based on the raw fairness perceptions, participants in the fault-based, lump-sum payment system in NSW considered the compensation process less fair than the participants in the no-fault, intermittent payment system in Victoria. The lower fairness perceptions concerned the claims process in general (e.g. claim lodgement, duration of the process, and the amount of compensation), how the claims manager dealt with the claim (e.g. objectiveness,

Table 5 Predictors of health post-injury

\begin{tabular}{|c|c|c|c|c|c|c|c|c|}
\hline \multirow[b]{3}{*}{ Independent variable } & \multicolumn{8}{|c|}{ Health post-injury } \\
\hline & \multicolumn{4}{|c|}{ Model 1} & \multicolumn{4}{|c|}{ Model 2} \\
\hline & $\overline{\mathrm{OR}}$ & $\mathrm{Cl}$ & & $p$ & $\mathrm{AOR}$ & $\mathrm{Cl}$ & & $p$ \\
\hline Fairness claims process & 2.78 & 1.45 & 5.33 & .002 & 2.83 & 1.40 & 5.71 & .004 \\
\hline Age & & & & & 1.01 & 0.99 & 1.04 & .23 \\
\hline Gender & & & & & 0.91 & 0.45 & 1.83 & .78 \\
\hline Country of birth & & & & & 1.00 & 0.48 & 2.12 & .99 \\
\hline Socio-economic status & & & & & 1.12 & 0.57 & 2.20 & .74 \\
\hline Education & & & & & 0.88 & 0.42 & 1.88 & .75 \\
\hline Marital status & & & & & 0.90 & 0.46 & 1.79 & .77 \\
\hline Injury & & & & & 1.35 & 0.57 & 3.16 & .49 \\
\hline Hospital admission & & & & & 2.04 & 0.97 & 4.26 & .06 \\
\hline Time after injury & & & & & 0.62 & 0.32 & 1.20 & .16 \\
\hline Health pre-injury & & & & & 6.15 & 1.09, & 34.61 & .04 \\
\hline
\end{tabular}

Note: Model 1 Nagelkerke $R^{2}=0.08$; Model 2 Nagelkerke $R^{2}=0.16$ Multiple logistic regression analysis, modelling the probability of good or excellent health (versus fair or poor health). Model 1 explores the unadjusted association between the overall fairness perception and health. Model 2 adjusts for demographic, injury variables, and pre-injury health. There was no multicollinearity

Coding: Overall fairness claims process $(0=$ disagree/neutral; $1=$ agree); Gender ( $0=$ Male; $1=$ Female); Country of birth ( $0=$ Other; $1=$ Australia); Socioeconomic status ( $0=$ Lower; $1=$ Higher); Education ( $0=$ Low/Medium; $1=$ High); Marital status ( $0=$ Single/Divorced; $1=$ Married); Injury $(0=$ Other; $1=$ Whiplash/ soft tissue injury); Hospital admission $(0=$ No; $1=$ Yes); Time after injury $(0=12$ months; $1=24$ months); Health pre-injury $(0=$ Poor; $1=$ Good); Health post-injury $(0=$ poor/fair, $1=$ good/excellent $)$. Reference category $=0$ 
prompt approval of treatment / other services) and how the claims manager interacted with the claimant (e.g. providing information, timely communication, being respectful). In contrast, participants in both states who had hired a lawyer were equally very satisfied with their lawyer, which indicates that NSW participants are not more negative overall. Participants in both states perceived the interaction with the medical assessor as being reasonably fair. The participants in NSW reported lower post-injury health status than in Victoria (note that these are raw comparisons without adjusting for sample differences).

The study also sought to determine whether differences in perceived fairness were associated with health status post injury. The analyses show that, after adjustment for demographic and injury characteristics, the overall perceived fairness of the compensation process was positively associated with the injured person's health. Those who perceived the overall compensation process to be fair were almost three times more likely to report good health outcomes. The association between perceived fairness and health recovery is consistent with what is shown in two previous studies [17, 23].

The elements negatively contributing to the overall fairness perception of the compensation process were lawyer involvement and medical assessments. The association between lawyer involvement and lower perceived fairness could be multidirectional. One possible direction is that lawyers could contribute to the perception of unfairness. Once a lawyer is involved, the compensation agency generally will ensure all requests for information or advice are sent directly to the claimant's legal representative [24], which means that the injured person's experiences depend on the information provided by the lawyer. However, lawyer involvement could also be the result of perception of unfairness and complexity of the scheme [25]. In the current study, the majority of participants involved a lawyer to assist with navigation of the compensation process, and participants indicated that the lawyer made the process easier, which seems to support the latter explanation, although the first one cannot be ruled out.

The association between medical assessments and lower perceived fairness could be explained by the fact that people who are medically assessed may consider that the purpose of assessment is to challenge the validity of their claim $[12,26]$. Our findings suggest that the medical assessment may be associated with lower perceived fairness because the medical assessor arranged by the insurer was considered to be biased.

Besides lawyer involvement and medical assessments, there are four system design differences that could explain the fairness difference. Firstly, the compensation systems differ in fault/no-fault nature. In NSW the insurance companies have to assess whether their client (i.e. the insured driver who was involved in the collision) was responsible/at-fault/liable for the crash whereas in Victoria compensation is provided regardless of fault. Liability assessment has been identified as a potential source of stress [13], as it can take up to 3 months to be decided, and therefore causes insecurity of and delay in compensation payments. It should be noted that we only included participants with accepted claims. Including participants whose claim was not accepted because liability was denied, could have resulted in a higher rate of perceived unfairness regarding the claim lodgement in NSW [13].

Secondly, in NSW in $100 \%$ of cases, someone else, aside from the participant was at least partially at-fault, whereas in Victoria $18 \%$ of participants indicated that they were at-fault. A subgroup analysis of the Victorian sample showed that those who were at-fault considered the process to be fairer than those who were not at all/ partially at fault $(\mathrm{t}(76)=-3.0, p=.004$; not reported in the result section), which is in line with a previous study [27]. Those who perceive themselves to have been at fault for their own injury could perceive the process to be fairer, being grateful to receive compensation despite the fact that they were at fault. Those whose injury is attributable to someone else's fault may want acknowledgment of the harm that has been inflicted. This need for acknowledgement is not always met which could lead to perceived unfairness [28].

Thirdly, Victoria has one state government compensation agency, whereas in NSW seven for-profit third-party insurance companies are in place. For-profit insurers have a stronger financial incentive to minimise the costs of compensation which may influence their actions. Injured persons might have less trust in for-profit, third-party insurance companies which could lead to poorer perceived fairness. The literature has shown that trust in authorities moderates procedural justice [29]. Further, there is likely to be a greater diversity of practices within the multiple insurance companies in NSW that influences perceived fairness, whereas in Victoria there is a single claims management agency with presumably less diversity in process.

The fourth difference is the frequency of compensation payment, in general, and the payment of loss of income, more specifically. In Victoria, loss of income is paid every two weeks to those who were working at the time of accident, whereas in NSW loss of income is paid as a lump sum at the settlement of the claim. As the average minor fault-based compensation claim takes two years to settle (personal communication with MAA), waiting that long for loss of income payments to be paid (at settlement) can create a significant financial burden $[11,30,31]$ and therefore be likely to contribute to lower fairness perceptions in NSW, among those who have not returned to work. Participants in Victoria were more 
likely to consider the compensation received so far to be acceptable than those in NSW. The chi square statistic was not as large as for the other items, possibly because only $12 \%$ of the NSW subsample indicated to be work disabled at the time of the interview.

A limitation of the current study is a possible selection bias, showing from the sample differences. For practical reasons, a different recruitment method was used in NSW versus Victoria (opt-in versus opt-out, participants were approached by a single person versus a research centre, and the research centre randomised the order of multi-item scales). Some differences (e.g. age, gender) could be due to the different recruitment method, others (e.g. in medical assessments, lawyer involvement) represent the actual circumstances in the compensation systems. It should also be noted that the findings may not be generalizable to other states or countries with either a fault or a no-fault system, because there are differences within fault-based systems and no-fault systems. A fault or no-fault system can be pure or modified with add-on no-fault or fault-based elements [22, 32]. Both NSW and Victoria have modified systems. As we selected only fault-based claims in NSW, the current findings may not be generalizable to all claimants in NSW. Similarly, the findings may not be generalizable to all claimants in Victoria, because we excluded common law (i.e. faultbased) claims. It should also be noted that systems in other countries operate in other social contexts, including variations in health care and other social benefits available, and that there may be other attitudes towards injury and social rights [22]. However, the elements discussed in this paper are present in all systems, and the aim is to generate a discussion about what design is anti-therapeutic and what we can do to improve the fairness experience. Finally, it is a cross sectional study, thus temporality cannot be assessed.

The research findings lead to potential suggestions for improvements. For example, applying first-party insurance instead of third-party insurance could increase perceived fairness, as the insurance company may be more committed to the injured person being a client. Furthermore, both the claims manager and the medical assessor could pay more attention to providing information before and after the medical assessment. A proposal to overcome potential bias in medical assessments is to have an independent organisation to broker the provision of examiners [26]. In addition, it seems better to provide interim payments rather than paying a lump sum at settlement, as this will provide financial security throughout the process, which is needed for the injured person to focus on recovery. It seems likely that these improvements will lead to improved perceived fairness. Improved perceived fairness may subsequently result in less lawyer involvement, which in turn may lead to greater well-being.

\section{Conclusion}

This study shows that there are differences in perceived fairness reported by injured people who lodge a compensation claim in two different compensation systems in Australia. The differences in fairness and in systems, together with the finding that perceived fairness is associated with the injured persons' health, suggests that the design of a compensation system can have a detrimental effect on the injured person's health and recovery.

An association between perceptions of unfairness and poorer recovery in the compensation process is concerning and politically important because compensation processes are designed to improve recovery. Although further research is required to validate and generalise the findings, the study could act as a catalyst to an evidence-based discussion on how to reduce anti-therapeutic aspects of the compensation process in order to improve the injured person's health and recovery after a motor vehicle crash.

\section{Abbreviations}

AOR, adjusted odds ratio; MAA, Motor Accidents Authority; NSW, New South Wales; SES, socio-economic status; TAC, transport accident commission

\section{Acknowledgements}

We acknowledge the TAC for funding the Victorian data collection and for their contribution to the design of the questionnaire. The MAA is acknowledged for assisting in the development and implementation of the study. Both the TAC and the MAA gave feedback on the design of the compensation systems and a previous draft of the manuscript. Finally, we acknowledge Dr. Genevieve Grant, Petrina Casey, and Darnel Murgatroyd for their contribution to the interpretation of the findings with reference to the two compensation schemes.

\section{Funding}

This work was supported by the Netherlands Organisation for Scientific Research (NWO) - Rubicon grant and by the Work Disability Prevention CIHR Strategic Training Program, through the Canadian Institutes of Health Research (CIHR) grant(s) FRN: 53909. IC's salary is supported by an Australian National Health and Medical Research Council Practitioner Fellowship.

Availability of data and materials

Data will be available upon request from the correspondence authors.

\section{Authors' contributions}

$\mathrm{NE}, \mathrm{AC}$ and IC designed the study, KLo collected the data, NE and SHJ analysed the findings, KLi gave important feedback from a legal and cross jurisdictional perspective; NE drafted the paper. AC, SHJ, KLi, KLO, and IC critically revised the paper. All authors approved the final version of the manuscript.

\section{Competing interests}

The authors declare that they have no competing interests.

\section{Consent for publication}

Not applicable.

\section{Ethics approval and consent to participate}

The research ethics committee of The University of Sydney approved the study (reference number: 2013/731).

\section{Author details}

'John Walsh Centre for Rehabilitation Research, Sydney Medical School Northern, University of Sydney, Sydney, Australia. ${ }^{2}$ Institute for Safety, Compensation and Recovery Research, Monash University, Melbourne, Australia. ${ }^{3}$ Institute for Work and Health, Toronto, Toronto. ${ }^{4}$ University of Ottawa, Ottawa, Canada. 
Received: 25 January 2016 Accepted: 21 July 2016

Published online: 29 July 2016

\section{References}

1. Connelly LB, Supangan R. The economic costs of road traffic crashes: Australia, states and territories. Accid Anal Prev. 2006;38(6):1087-93.

2. Cutter A. Comparison across CTP schemes. Australasia: Institute of Actuaries of Australia; 2007.

3. Motor Accidents Authority: Reforms to the NSW Compulsory Third Party Green Slip Insurance Scheme 2013. [http://www.maa.nsw.gov.au/_data/ assets/pdf_file/0018/13329/Reforms_to_the_NSW_CTP_Green_Slip_ Insurance_Scheme_February_2013.pdf, Accessed 15 Jan 2016].

4. The Royal Australasian College of Physicians. Compensable injuries and health outcomes. Sydney: The Royal Australasian College of Physicians; 2001.

5. Harris I, Mulford J, Solomon M, van Gelder JM, Young J. Association between compensation status and outcome after surgery: a meta-analysis. JAMA. 2005;293(13):1644-52.

6. Elbers NA, Hulst L, Cuijpers P, Akkermans AJ, Bruinvels DJ. Do compensation processes impair mental health? A meta-analysis. Injury. 2013;44(5):674-83.

7. Shuman DW. When time does not heal: understanding the importance of avoiding unnecessary delay in the resolution of tort cases. Psychol Public Policy Law. 2000;6(4):880.

8. Cotti A, Magalhães T, Pinto Da Costa D, Matos E. Road traffic accidents and secondary victimisation: the role of law professionals. Med Law. 2004:23:259-68.

9. Grant GM, O'Donnell ML, Spittal MJ, Creamer M, Studdert DM. Relationship between stressfulness of claiming for injury compensation and long-term recovery: a prospective cohort study. JAMA Psychiatry. 2014;71(4):446-53.

10. Lippel K. Workers describe the effect of the workers' compensation process on their health: a Quebec study. Int J Law Psychiatry. 2007;30(4-5):427-43.

11. MacEachen E, Kosny A, Ferrier S, Chambers L. The "toxic dose" of system problems: why some injured workers don't return to work as expected. J Occup Rehabil. 2010;20(3):349-66.

12. Murgatroyd D, Lockwood K, Garth B, Cameron ID. The perceptions and experiences of people injured in motor vehicle crashes in a compensation scheme setting: a qualitative study. BMC Public Health. 2015;15:423.

13. Elbers NA, Akkermans AJ, Lockwood K, Craig A, Cameron ID. Factors that challenge health for people involved in the compensation process following a motor vehicle crash: a longitudinal study. BMC Public Health. 2015;15:339.

14. Kilgour E, Kosny A, McKenzie D, Collie A. Healing or harming? Healthcare provider interactions with injured workers and insurers in Workers' compensation systems. J Occup Rehabil. 2014;25(1):220-39.

15. Gabbe BJ, Sleney JS, Gosling CM, Wilson K, Sutherland A, Hart M, Watterson D, Christie N. Financial and employment impacts of serious injury: a qualitative study. Injury. 2014;45:1445-51.

16. Field A. Discovering statistics using IBM SPSS statistics. London: Sage; 2013.

17. Elbers NA, Akkermans AJ, Cuijpers P, Bruinvels DJ. Procedural justice and quality of life in compensation processes. Injury. 2013:44(11):1431-6.

18. MacDonald S. Information paper: an introduction to Socio-Economic Index for Areas (SEIFA). Canberra: Australian Bureau of Statistics; 2008.

19. Ware Jr JE, Kosinski M, Keller SD. A 12-item short-form health survey: construction of scales and preliminary tests of reliability and validity. Med Care. 1996;34(3):220-33.

20. Colquitt JA. On the dimensionality of organizational justice: a construct validation of a measure. J Appl Psychol. 2001;86:386-400.

21. Franche R-L, Severin CN, Lee H, Hogg-Johnson S, Hepburn CG, Vidmar M, MacEachen E. Perceived justice of compensation process for return-to-work: development and validation of a scale. Psychol Inj Law. 2009;2(3-4):225-37.

22. Carroll LJ, Connelly LB, Spearing NM, Cote P, Buitenhuis J, Kenardy J. Complexities in understanding the role of compensation-related factors on recovery from whiplash-associated disorders: discussion paper 2. Spine (Phila Pa 1976). 2011;36(25 Suppl):S316-321.

23. Sullivan MJ, Yakobov E, Scott W, Tait R. Perceived injustice and adverse recovery outcomes. Psychol Inj Law. 2014;7:325-34

24. Motor Accidents Authority: Claims handling guidelines for CTP Insurers. In. http://www.maa.nsw.gov.au/media/publications/about-us/maa-claimshandling-guidelines, Accessed 15 Jan 2016.

25. Casey P, Feyer AM, Cameron ID. Associations with legal representation in a compensation setting 12 months after injury. Injury. 2015;46(5):918-25.
26. Kilgour B, Kosny A, Akkermans AJ, Collie A. Procedural justice and the use of independent medical evaluations in Workers' compensation. Psychol Inj Law. 2015;8:153-68.

27. Thompson J, Berk M, O'Donnell M, Stafford L, Nordfjaern T. The association between attributions of responsibility for motor vehicle accidents and patient satisfaction: a study within a no-fault injury compensation system. Clin Rehabil. 2014;29(5):500-8.

28. Akkermans AJ. Reforming personal injury claims settlement: Paying more attention to emotional dimension promotes victims recovery. Available at SSRN: http://ssrn.com/abstract=1333214. 2009. Accessed 15 Jan 2016.

29. Van den Bos K, Wilke HA, Lind EA. When do we need procedural fairness? The role of trust in authority. J Pers Soc Psychol. 1998;75(6):1449.

30. Greenough CG, Fraser RD. The effects of compensation on recovery from low-back injury. Spine (Phila Pa 1976). 1989;14(9):947-55.

31. Roberts-Yates $C$. The concerns and issues of injured workers in relation to claims/injury management and rehabilitation: the need for new operational frameworks. Disabil Rehabil. 2003;25(16):898-907.

32. Fronsko AL. No-fault v. common law. Brisbane: Overview of Australian Compulsory Third Party (CTP) Insurance Schemes \& 75 years of debate no-fault v. common law compensation for the victims of motor vehicle accidents; 2001

33. Transport Accident Act 1986. In. http://www.tac.vic.gov.au/about-the-tac/ our-organisation/legislation-and-regulations, accessed on 15 Jan 2016.

34. Motor Accidents Compensation Act 1999. In. http://www.maa.nsw.gov.au/ about-us/about-the-nsw-ctp-scheme/legislation, accessed on 15 Jan 2016.

35. Clay FJ, Berecki-Gisolf J, Collie A. How well Do We report on compensation systems in studies of return to work: a systematic review. J Occup Rehabil. 2013;24(1):111-24.

\section{Submit your next manuscript to BioMed Central and we will help you at every step:}

- We accept pre-submission inquiries

- Our selector tool helps you to find the most relevant journal

- We provide round the clock customer support

- Convenient online submission

- Thorough peer review

- Inclusion in PubMed and all major indexing services

- Maximum visibility for your research

Submit your manuscript at www.biomedcentral.com/submit

) Biomed Central 